\title{
A GUERRA DOS HOMENS E A VIDA DAS MULHERES. AS INTERFACES ENTRE PLANEJAMENTO URBANO, VIOLÊNCIA CONTRA A MULHER E SEGURANÇA PÚBLICA NO RIO DE JANEIRO, BRASIL
}

\author{
Poliana Gonçalves Monteiro* \\ *Universidade Federal Fluminense, Escola de Arquitetura e Urbanismo, Programa de Pós-graduação em \\ Arquitetura e Urbanismo, Niterói, RJ, Brasil
}

\begin{abstract}
Resumo
O presente artigo objetiva discutir a invisibilidade da violência contra as mulheres na agenda da segurança pública e os efeitos da violência urbana com base em sua interface com o planejamento urbano. Nesse sentido, busca-se demonstrar os efeitos da violência urbana na vida das mulheres, evidenciando o padrão territorial desigual em que a violência contra a mulher se expressa na cidade do Rio de Janeiro e o modo como essa seletividade é estruturada e estruturante pelo/do patriarcado em sua interseccionalidade com raça e classe. Além disso, é parte fundamental da análise observar a territorialização da violência contra a mulher em relação à implementação de outras políticas públicas, aqui com o enfoque voltado à política de segurança pública. A reflexão desenvolvida neste texto fundamenta-se nos dados sobre morte violenta de mulheres na cidade do Rio de Janeiro disponibilizados pelo Instituto de Segurança Pública do estado do Rio de Janeiro (ISP).

Palavras-chave

Segurança Pública; Violência contra Mulher; Patriarcado; Violência Urbana; Planejamento Urbano; Machismo Institucional.
\end{abstract}




\title{
THE WAR OF MEN AND THE LIVES OF WOMEN. THE INTERFACES BETWEEN URBAN PLANNING, VIOLENCE AGAINST WOMEN AND PUBLIC SECURITY IN RIO DE JANEIRO, BRAZIL
}

\author{
Poliana Gonçalves Monteiro* \\ *Universidade Federal Fluminense, Escola de Arquitetura e Urbanismo, Programa de Pós-graduação em \\ Arquitetura e Urbanismo, Niterói, RJ, Brazil
}

\begin{abstract}
This paper intends to discuss the invisibility of violence against women on the public security agenda and the effects of urban violence from its interface with urban planning. In this sense, we aim to demonstrate the effects of urban violence on women's lives, highlighting the uneven territorial pattern in which violence against women is expressed in the city of Rio de Janeiro and how this selectivity is structured and structuring by the patriarchy in its intersectionality with race and class. In addition, it is a fundamental part of the analysis to observe the territorialization of violence against women in relation to the implementation of other public policies, here, especially the public security policy. The reflection developed in this text will be based on data on the violent death of women in the city of Rio de Janeiro provided by the Institute of Public Security of the State of Rio de Janeiro (ISP).

Keywords

Public Security; Violence against Women; Patriarchy; Urban Violence; Urban Planning; Institutional Sexism.
\end{abstract}




\section{A GUERRA DOS HOMENS E A VIDA DAS MULHERES. AS INTERFACES ENTRE PLANEJAMENTO URBANO, VIOLÊNCIA CONTRA A MULHER E SEGURANÇA PÚBLICA NO RIO DE JANEIRO, BRASIL}

Poliana Gonçalves Monteiro

1. Introdução

A ocorrência de crimes violentos nas grandes cidades brasileiras cresceu significativamente nas últimas décadas, posicionando a violência urbana como um dos principais problemas da agenda pública. Nesse contexto, a função de controle social dos aparelhos policiais se tornou foco de atenção, centrando o debate na “dimensão coercitiva de repressão ao crime violento" (MACHADO DA SILVA, 2010, p. 284). A violência contra a mulher, por outro lado, segue de forma inconsistente na agenda da segurança pública, com as ações de enfrentamento direcionadas quase que exclusivamente ao atendimento às vítimas sobreviventes, o que, apesar dos avanços no debate, considerando as "gradações de visibilidade" (FARIAS, 2015), contribui para que esse tipo de violência sistêmica continue posicionado como uma questão da esfera privada.

Nesse sentido, o presente artigo busca desvelar a possível interface entre planejamento urbano e os efeitos da violência urbana na vida das mulheres, evidenciando o padrão territorial desigual no qual a violência contra a mulher se expressa na cidade do Rio de Janeiro em sua interseccionalidade com raça e classe. A interseccionalidade é uma ferramenta metodológica em disputa cunhada por Kimberlé Crenshaw no âmbito das leis antidiscriminação. A sensibilidade analítica da interseccionalidade teoriza sobre a sugestão histórica pensada pelo movimento de mulheres negras e evidencia a inseparabilidade estrutural do racismo, do capitalismo e do cis-heteropatriarcado (AKOTIRENE, 2019). 
O conceito, de acordo com Collins (2017), é forjado no contexto da urgência de tradução das ideias dos movimentos sociais de liberdade, equidade, justiça social e democracia participativa para formatos que fossem reconhecidos no campo da produção do conhecimento. O contorno dado ao conceito de interseccionalidade nos espaços legitimados de produção de conhecimento se consolida como uma “forma de investigação crítica e práxis” (COLLINS, p. 7), proporcionando modos sugestivos de enxergar o mundo que considerassem diferentes níveis de poder. $\mathrm{Ou}$ seja, a interseccionalidade tem como objetivo conectar dois polos da produção do conhecimento: "a produção intelectual de indivíduos com menos poder, que estão fora [...] de instituições similares de produção de conhecimento, e o conhecimento que emana primariamente de instituições cujo propósito é criar saber legitimado" (COLLINS, p. 7). Nesse sentido, a efetividade das principais ideias da interseccionalidade destaca o debate sobre a relevância da disputa da produção do conhecimento para a luta por liberdade e justiça social (COLLINS, p. 7). O objetivo da justiça social, portanto, está imbricado com o reconhecimento epistemológico do mesmo estatuto teórico da classe social para gênero e raça/etnia (SAFFIOTI, 2000).

Além disso, é parte fundamental da análise observar a territorialização da violência contra a mulher em relação à implementação de outras políticas públicas. Para isso, são analisados territorialmente os dados sobre violência contra a mulher na cidade como caso concreto que, de maneira dialógica, evidencia os padrões de vulnerabilidade debatidos na bibliografia brasileira e internacional especializada no tema da violência urbana, com o intuito de contribuir para a reflexão a esse respeito nas grandes cidades sob a perspectiva da vida das mulheres.

A dicotomia entre o público e o privado é uma questão fundamental da teoria feminista, pois essa oposição, socialmente construída, dissimula a submissão das mulheres pelos homens dentro de uma ordem supostamente universal, igualitária e individualista. Assim, a cisão entre as esferas pública e privada se relaciona com a perspectiva universalista da esfera pública e com a constituição das noções de direitos individuais', que ocultam a relação intrínseca entre essas duas esferas na conformação das identidades. A perspectiva universalista que rege a compreensão sobre a esfera pública discute a sociedade civil abstraída e apartada da esfera privada doméstica e é concebida à imagem e semelhança dos homens, ou seja, "os critérios aparentemente universais que regem a sociedade civil são, na verdade, aqueles associados à concepção liberal do indivíduo do sexo masculino" (PATEMAN apud MIGUEL; BIROLI, 2013, p. 60).

1. Os direitos individuais previstos na Constituição Federal de 1988 são: direito à vida; direito à intimidade; direito de igualdade; direito de liberdade; direito de propriedade. 
O caráter patriarcal, racista e capitalista do planejamento urbano determina a carência de serviços básicos - como creches, escolas, hospitais, moradia adequada, parques infantis, áreas verdes -, o que amplia a vulnerabilidade da vida cotidiana das mulheres, em geral responsabilizadas pelo cuidado e pela produção da vida. O planejamento urbano, nesse sentido, pode reforçar a dicotomia entre o público e o privado. A divisão sexual do trabalho ${ }^{2}$ e a consequente responsabilização pelos trabalhos reprodutivos ${ }^{3}$ complexifica o cotidiano das mulheres em sua relação com o espaço urbano, exigindo o equilíbrio entre as atividades relativas à sua moradia, um espaço privado, e os espaços públicos da cidade. Nas grandes cidades, a mobilidade e a acessibilidade são parâmetros espaciais significativos na construção de autonomia das mulheres, mas atualmente se baseiam no movimento pendular casa-trabalho, que toma como padrão o cotidiano dos homens. Por outro lado, é importante destacar que o equilíbrio entre o público e o privado é uma exigência do capitalismo patriarcal sustentado pelo regime de exploração-dominação.

O objetivo aqui, portanto, é compreender se o planejamento urbano, tal como é gestado e gerido no presente, pode ser um elemento de aprofundamento da violência contra a mulher nas grandes cidades. Fazendo uso de dados quantitativos territorializados, que acreditamos elucidar a experiência das mulheres cariocas em sua vivência urbana, com enfoque nas periferizadas e negras, buscamos desvelar a relação entre políticas públicas, violência e planejamento urbano com base na chave da interseccionalidade. Acreditamos, ainda, que existem imbricações entre violência urbana e a violência contra a mulher e que as políticas públicas urbanas implementadas no Rio de Janeiro nos últimos anos podem ser um fator relevante para a compreensão da vulnerabilidade das mulheres. Nesse sentido, o conceito de interseccionalidade se constitui em elemento estruturante de uma análise capaz de compreender a relação entre raça, gênero e classe em sua materialização no espaço urbano. No que tange ao campo de estudos sobre violência urbana, tema amplo e polissêmico, optamos aqui por dialogar com especialistas brasileiros que debatem profundamente a cidade do Rio de Janeiro. Recorremos também à análise de Perry (2017), que evidencia a violência como ação sancionada pelo Estado brasileiro.

\footnotetext{
2. Existem diversas abordagens sobre a divisão sexual do trabalho. Utilizamos aqui a proposição de Hirata e Kergoat (2007) para sua conceituação como um projeto político feminista que busca pensar o trabalho de forma não centrada na valorização do capital, mas no que as autoras chamam de "produção do viver”. HIRATA, H.; KERGOAT, D. Novas configurações da divisão sexual do trabalho. Cadernos de Pesquisa, v. 37, n. 132, p. 595-609, set.-dez. 2007. Disponível em: http://www.scielo.br/pdf/cp/v37n132/ a0537132.pdf. Acesso em: 10 nov. 2013.

3. O trabalho reprodutivo é posicionado como apêndice do trabalho assalariado, que atribui exclusivamente à mulher a tarefa de conciliação com o chamado trabalho produtivo e a demanda de cuidado com os dependentes e ainda reafirma o status quo segundo o qual mulheres e homens não são iguais diante do trabalho profissional (HIRATA; KERGOAT, 2007).
} 
Essa análise considera que o patriarcado 4 se baseia no controle e na imposição do medo sobre as mulheres e autoriza a violência de gênero por meio de uma organização social que privilegia o masculino (SAFFIOTI, 2011). A violência é compreendida usualmente como a ruptura de qualquer forma de integridade da vítima, seja física, psíquica, sexual, moral ou patrimonial (SAFFIOTI, 2011), enquanto no campo dos estudos urbanos pode ser compreendida como a ruptura forçada das rotinas (MACHADO DA SILVA, 2010) consideradas essenciais para a produção e a reprodução do capitalismo racista e patriarcal. No que concerne à vida cotidiana nas grandes cidades, de acordo com Marouli (1995, p. 544; tradução nossa), "o espaço dá uma forma tangível às limitações sociais da vida das mulheres”. Por outro lado, as ações do Estado em territórios cuja população é predominantemente negra não podem ser interpretadas simplesmente como política de contenção, e sim como a implementação de uma política de exclusão ligada consistentemente à produção capitalista, racista e patriarcal das cidades.

A ação policial violenta não é apenas uma rotina, mas uma normativa que reverbera nas cidades brasileiras e em todo o mundo. Essa violência, segundo Perry (2017), tem várias formas, que incluem tortura policial e assassinato, assim como violências sociais que abrangem desemprego e falta de moradia adequada. Esse processo é complexo e se relaciona intimamente com a militarização da vida, cuja face mais evidente se manifesta com a ideia de "policiamento eficaz" que acompanha tanto as propostas de treinamento militarista das forças policiais (PERRY, 2017) como a própria implantação das Unidades de Polícia Pacificadora (UPPs) no Rio de Janeiro e a imbricação entre polícia, milícia e tráfico na cidade.

Por outro lado, é preciso considerar que a dinâmica da militarização da vida expressa pela correlação de força entre os grupos armados atuantes no Rio de Janeiro se modificou profundamente nos últimos anos. O poder das milícias sobre diversos territórios em toda a cidade e região metropolitana se ampliou de maneira dramática desde 2007, alterando o quadro anterior no qual a principal questão criminal carioca estava centrada na disputa entre facções associadas ao tráfico de drogas (HIRATA et al., 2021). Nesse sentido, de acordo com esses autores (HIRATA et al., 2021, p. 5), "a principal diferença entre os grupos de milicianos e as facções criminais já não reside tanto nos mercados que fornecem as bases econômicas para a sua reprodução [...] e sim nos tipos de atores que integram essas organizações”, ou seja, a participação de agentes públicos na sua estrutura confere às milícias vantagens políticas para atuação em relação às facções associadas

\footnotetext{
4. Para a conceituação do termo "patriarcado", utilizamos também o trabalho da socióloga brasileira Heleieth Saffioti (2011), que o define como um regime de dominação e exploração contínuo exercido pelos homens sobre as mulheres.
} 
diretamente ao tráfico, ampliando, inclusive, a capacidade de geração de renda. O possível impacto da expansão do poder das milícias na vida das mulheres será abordado posteriormente.

Nesse sentido, destacamos duas dimensões institucionais da luta feminista pelo enfrentamento da violência contra a mulher, elemento aqui considerado estruturante do regime opressão-dominação patriarcal, capitalista e racista: i) a ausência estratégica do Estado democrático de direito em "territórios da pobreza", os quais, de acordo com Machado da Silva (2010), são mais intensamente afetados tanto pela violência policial como pela criminal, o que certamente não indica nenhuma causalidade com as disposições morais ou com a conduta da população residente; ii) a presença precarizada do Estado como responsável pela infraestrutura básica, serviços e políticas públicas, o que vulnerabiliza as áreas historicamente periferizadas, empobrecidas e em geral habitadas por população predominantemente negra.

O artigo estrutura-se em quatro seções além desta introdução. A primeira apresenta a metodologia desenvolvida para discutir a invisibilidade da violência contra a mulher na agenda da segurança pública e os efeitos da violência urbana na vida das mulheres em sua interface com o planejamento urbano. Na segunda seção, são destacados os limites e as potencialidades da pesquisa territorializada sobre violência contra a mulher, considerando a possibilidade de existência do mecanismo "machismo institucional" que estrutura o planejamento e a gestão da cidade do Rio de Janeiro, com base em premissas patriarcais. Em seguida, desenvolve-se uma reflexão sobre o paradigma masculino da segurança pública, indicando as permanências e os possíveis avanços no debate e na legislação relacionada ao enfrentamento da violência contra a mulher. A última seção aborda a conexão entre a violência epistêmica, que as invisibiliza como sujeitas na produção do conhecimento, e a violência contra a mulher, que vulnerabiliza as rotinas de milhares de mulheres e estrutura a opressão sexista. Assim, é utilizada a análise quantitativa dos dados disponíveis para pensar sobre a forma desigual em que a violência contra a mulher se expressa nessa "cidade patriarcal". Os dados analisados demonstram que as regiões com maiores taxas de morte violenta de mulheres, por exemplo, são territórios em que, por um lado, o Estado, como responsável pela provisão de infraestrutura, serviços e políticas públicas, está precariamente presente, e, por outro, o Estado democrático de direito, que deveria garantir o respeito das liberdades civis e os direitos humanos mediante o estabelecimento de uma proteção jurídica, não se efetiva. Isso, por sua vez, resulta na violência policial e criminal, que se manifesta, em alguns casos, pela presença ostensiva dos poderes paraestatais, seja milícia, seja tráfico, e da polícia violenta. A reflexão aqui desenvolvida, portanto, 
não consente com a narrativa sobre a ausência do Estado ou com a percepção sobre uma dicotomia entre crime e Estado, mas busca contribuir para que reflitamos sobre a implicação da militarização da vida para a perpetuação da violência contra a mulher.

1. Metodologia

O presente trabalho busca discutir a invisibilidade da violência contra a mulher na agenda da segurança pública e os efeitos da violência urbana na vida das mulheres em sua interface com o planejamento urbano. Nesse sentido, pretende-se demonstrar os efeitos da violência urbana, evidenciando o padrão territorial desigual em que a violência contra a mulher se expressa na cidade do Rio de Janeiro, o modo como essa seletividade é estruturada e estruturante pelo/do regime de exploração-dominação patriarcal, racista e capitalista. Além disso, é parte essencial da análise observar a territorialização da violência contra a mulher no tocante à implementação de outras políticas públicas, sobretudo a de segurança pública. A reflexão desenvolvida neste artigo baseia-se nos dados sobre morte violenta de mulheres na cidade do Rio de Janeiro disponibilizado pelo ISP, utilizando bibliografia especializada no tema da violência urbana. Tais informações têm como fonte o banco de dados dos registros de ocorrência (RO) das delegacias de polícia do estado do Rio de Janeiro, fornecidos pelo Departamento Geral de Tecnologia da Informação e Telecomunicações (DGTIT).

Entretanto, os registros policiais representam apenas uma estimativa dos crimes ocorridos, reconhecidamente subestimada, em virtude, dentre outros fatores, à subnotificação. Assim, os dados oficiais de criminalidade estão sujeitos a uma série de limitantes, refletindo o processo social de notificação de crimes, e não o universo dos que foram de fato cometidos em determinado local. Nessa análise, é preciso considerar que diversos fatores podem interferir no comportamento dos fenômenos criminais: o contingente populacional, a extensão do território, a influência da população flutuante sobre a população residente, a concentração populacional em determinadas áreas, a existência de redes de serviços e investimentos, entre outros. Apesar de possíveis distorções, acreditamos que esses dados permitem visualizar um panorama da situação de vida das mulheres na cidade do Rio de Janeiro. Também se fez uso de dados territorializados do recenseamento demográfico nacional, o Censo 2010 (IBGE, 2012).

O recorte temporal da pesquisa tem o objetivo de apreender o processo de construção da agenda da Segurança Pública no Rio de Janeiro a partir de 2008 utilizando como marco a instalação da primeira UPP, em 19 de dezembro daquele ano, no Morro de Santa Marta. Esse marco objetiva relacionar os dados sobre violência 
contra a mulher relativos ao ano de 2010 que foram tabulados e tratados com a intenção de contribuir para a composição de uma visão geral das taxas de violência contra a mulher por bairros, os quais, por sua vez, integram as Circunscrições Integradas de Segurança Pública (CISP) ${ }^{5}$. Para apresentar os dados de forma mais sintética e consequentemente facilitar sua apreensão, e ainda dialogar com a literatura existente sobre o tema, optou-se aqui por realizar a maior parte das análises por CISP. Porém, em virtude de a extensão territorial dessas instâncias geográficas ${ }^{6}$ não permitir a observação das desigualdades internas e das peculiaridades locais, serão apresentadas também as taxas de morte violenta de mulheres por bairro, como forma de aproximá-las das características territoriais que podem ser relevantes para a compreensão da relação entre a violência contra a mulher e as desigualdades urbanas em sua conexão com a interseccionalidade. Não se desconsidera, contudo, que os bairros também são instâncias geográficas muitas vezes extensas que não refletem necessariamente as desigualdades internas de amplos territórios, mas, diante da característica dos dados obtidos, são a aproximação possível.

Com base nessas análises, o objetivo é evidenciar a invisibilidade da violência contra a mulher no debate sobre segurança pública ancorado na territorialização dos casos de morte violenta de mulheres ${ }^{7}$ no Rio de Janeiro em contraposição ao discurso hegemônico e patriarcal sobre violência e às políticas públicas pensadas para seu enfrentamento - no caso, as UPPs. Para essa análise, portanto, foi utilizado o cálculo da taxa por 10 mil mulheres ${ }^{8}$ para o crime de homicídio doloso, para cada bairro da cidade e respectivas CISPs, agregando as informações de população por bairro do Censo $2010^{9}$, como meio para observar o padrão territorial desse tipo de violência.

5. Foram criadas pelo Decreto estadual $n^{0} 41.930$ e caracterizam, segundo o novo modelo de integração geográfica utilizado pelo ISP do estado do Rio de Janeiro, a menor instância de apuração dos indicadores de criminalidade. Disponível em: http://www.isp.rj.gov.br/Conteudo.asp?ident=38. Acesso em: 25 ago. 2019.

6. "Instância geográfica” é o termo utilizado pelo ISP que expressa determinado recorte territorial.

7. A utilização da expressão feminicídio é estratégica para diferenciar os assassinatos de mulheres do conjunto de homicídios e evidenciar o caráter estrutural desse tipo de violência. No entanto, nem todos os homicídios dolosos cometidos contra mulheres são motivados por razões de gênero. Além disso, o feminicídio foi tipificado somente em 2015. Nesse sentido, aqui será utilizado o termo "morte violenta de mulheres".

8. A Comissão Econômica para a América Latina e o Caribe (Cepal) recomenda que a produção de estatísticas de gênero seja padronizada com a produção de indicadores de violência por meio de taxas por 100 mil e por 10 mil mulheres. Para o cálculo das taxas por bairro, devido ao menor contingente populacional, fez-se uso de uma variação com o cálculo para mil mulheres.

9. A distância temporal do Censo 2010, assim como as grandes transformações urbanas que provocaram o deslocamento compulsório de parcela significativa da população, impossibilita o cálculo das projeções para a população feminina por CISP, o que permitiria a análise por taxa de 10 mil mulheres para outros anos. 
A potência da interseccionalidade como ferramenta metodológica se apresenta aqui de maneira ainda experimental por meio do cruzamento dos dados de raça e renda de forma territorializada em sua possível conexão com as ocorrências de casos fatais de violência contra a mulher. O aprofundamento da conexão entre o planejamento urbano e territorial, as políticas públicas e seu impacto na vida das mulheres é um desafio coletivo que certamente não se encerra neste artigo. Essa reflexão pretende se constituir em um chamamento para o diálogo e para a reflexão, reconhecendo a importância da disputa da produção do conhecimento pautado em uma epistemologia radicalmente feminista e que explora a interseccionalidade como práxis de pesquisa. A pesquisa territorializada dos dados sobre violência contra a mulher é urgente, mas apresenta limites. Estes se relacionam com as características intrínsecas a dados desse tipo, considerando que os registros policiais são apenas uma estimativa dos crimes ocorridos, em geral subestimada; com a ausência de dados censitários mais atualizados que permitiriam a comparação mais acurada da atualidade; mas também com a metodologia, que deve ser constantemente revisitada e aprofundada.

\section{O machismo institucional no planejamento urbano}

A reflexão sobre o caráter interseccional da desigualdade materializada na cidade sugere que, em termos objetivos, as demandas para ampliar o acesso das mulheres à cidade não foram definidas e são dissimuladas pelo direcionamento da questão de gênero ${ }^{10}$ para o domínio do privado, ou para questões simplificadas e individualizadas. As desigualdades de gênero no geral são interpretadas como conflito entre indivíduos, e não como questão pública e política ${ }^{11}$. O debate sobre "racismo institucional" questiona os esquemas que interpretam as desigualdades raciais como produtos de ações individuais, demonstrando que há mecanismos estruturais de discriminação que operam inclusive por meio de políticas públicas (SILVÉRIO apud LEITE, 2012b). Entendemos aqui que, com parâmetros análogos, está em vigência um mecanismo de discriminação de gênero que é estrutural, e, embora não seja finalístico, acaba resultando na manutenção do regime de exploração-dominação patriarcal: o “machismo institucional”.

\footnotetext{
10. O conceito de gênero será utilizado aqui como categoria geral que contribui para a problematização pretendida, mas que não a compreende em sua totalidade. O caráter abstrato desse conceito e sua constante vinculação ao privado, que, na perspectiva hegemônica é essencialmente apolítico, determinam sua ambiguidade. Sobre esse debate, ver Saffioti (2000).

11. Como exemplo da compreensão do debate de gênero como algo referente à esfera privada, pode-se mencionar que somente em 2020 o Supremo Tribunal Federal brasileiro entendeu como inconstitucional o projeto de lei que proibia o debate sobre gênero nas escolas brasileiras.
} 
Os impactos da periferização da moradia na vida das mulheres, tal como descreve Marouli (1995), são amplificados no contexto das remoções forçadas, que alargam a dicotomia entre público e privado e promovem a ruptura com as relações de vizinhança e redes de apoio, o que limita ainda mais o cotidiano das mulheres. Vale destacar que na cidade do Rio de Janeiro, no período entre 2009 e 2014, foram removidas cerca de 22 mil famílias com a justificativa de realizar as transformações urbanas relacionadas aos megaeventos esportivos ${ }^{12}$ (FAULHABER; AZEVEDO, 2015). As unidades habitacionais destinadas ao reassentamento dessas famílias foram construídas majoritariamente nas áreas mais periféricas e empobrecidas da cidade, onde há os maiores índices de violência contra a mulher. Os espaços de constrangimento, como a rua em determinados locais e horários, ou espaços de confinamento, como as residências em periferias distantes, são a materialização das diferenças de acesso à cidade de homens e mulheres (SILVA, 2007). O zoneamento urbano inerente ao planejamento urbano modernista racionalista (machista e patriarcal) reafirma a divisão sexual do trabalho, ao fragmentar a cidade em áreas direcionadas a usos específicos.

Assim, a violência urbana não afeta toda a população de modo homogêneo. Nos territórios populares e empobrecidos, segundo Machado da Silva (2010), a "sociabilidade violenta"13 determina condições críticas para a população moradora. Nesses territórios, demarcados como "zonas de não-ser”, a presença da população predominantemente negra predetermina a intenção estatal de matar por meio da ação policial violenta ou pela negação de bens sociais e serviços (PERRY, 2017). Além disso, é possível considerar que, enquanto os homens morrem na linha de frente nessa "guerra" promovida pelo Estado, as mulheres sucumbem invisíveis aos efeitos do contexto da "sociabilidade violenta". A reflexão aqui desenvolvida tem o intuito de evidenciar o padrão territorial desigual em que a violência contra a mulher se materializa na cidade do Rio de Janeiro e a maneira pela qual essa seletividade é estruturada e estruturante pelo/do regime de exploração-dominação patriarcal, racista e capitalista. Embora sejam evidentes os limites da análise dos registros de ocorrências da violência para apreender o universo dos crimes realmente cometidos em determinado local, esses dados conformam um suporte

12. Para maiores informações sobre os megaeventos esportivos no Brasil, ver, entre outros: VAINER, C.; BROUDEHOUX, A. M.; SÁNCHEZ, F.; OLIVEIRA, F. (org.). Os megaeventos e a cidade: perspectivas críticas. Rio de Janeiro: Letra Capital, 2016 e COSENTINO, R.; MONTEIRO, P. Rio 2016: projeto, orçamento e (des) legados olímpicos. Rio de Janeiro: Fundação Heinrich Böll, 2017. v. 1. p. 43.

13. A noção de "sociabilidade violenta" desenvolvida por Machado da Silva (2010) pretende analisar a violência não como um fenômeno imanente de certas regiões da cidade, o que poderia legitimar a criminalização da pobreza, mas como uma ferramenta de análise que complexifica o fenômeno da violência urbana. 
para discutir e conceber políticas públicas integradas que se mostrem capazes de romper com o "machismo institucional".

Nesse sentido, a territorialização dos casos de morte violenta de mulheres no Rio de Janeiro pode contribuir para evidenciar a invisibilidade da violência contra a mulher no debate sobre segurança pública. O cálculo da taxa por 10 mil mulheres para o crime de homicídio doloso de mulheres, para cada CISP da cidade, agregando as informações de população por bairro do Censo 201014, permite observar o padrão territorial desse tipo de violência. A Tabela 1 demonstra que, com exceção da região central da cidade, cuja taxa é influenciada negativamente pela grande importância da população flutuante e pela reduzida população residente, as regiões com as maiores taxas de morte violenta de mulheres são os territórios onde a militarização é expressa pela imbricada e confusa tríade polícia violenta, milícia e tráfico.

\begin{tabular}{c|l|c} 
CISP & Bairros & Taxa \\
\hline $1^{\mathrm{a}}, 4^{\mathrm{a}}, 5^{\mathrm{a}}$ & Centro, Gamboa, Santo Cristo, Saúde, Lapa, Paquetá & 1,574 \\
\hline $36^{\mathrm{a}}$ & Paciência, Santa Cruz & 0,988 \\
\hline $39^{\mathrm{a}}$ & Acari, Barros Filho, Costa Barros, Parque Colúmbia, Pavuna & 0,863 \\
\hline $35^{\mathrm{a}}$ & Campo Grande, Cosmos, Inhoaíba, Santíssimo, Senador Vasconcelos & 0,669 \\
\hline $43^{\mathrm{a}}$ & Guaratiba, Pedra de Guaratiba, Sepetiba & 0,662 \\
\hline $11^{\mathrm{a}}$ & Rocinha & 0,569 \\
\hline
\end{tabular}

Tabela 1. Morte violenta por taxa de 10 mil mulheres por CISP em 2010

Fonte: Elaborada pela autora.

A intenção deste texto não é necessariamente criar uma conexão finalística entre a presença de poderes paraestatais e da polícia violentamente letal e a incidência de violência contra a mulher. $\mathrm{O}$ que se pretende é sugerir, em primeiro lugar, que, no contexto da "sociabilidade violenta" presente na vida militarizada dos "territórios da pobreza", as mulheres estão mais vulneráveis ao ciclo da violência ${ }^{15}$ que pode culminar no feminicídio. E, em segundo lugar, que a premissa do debate da segurança pública, embebida do "machismo institucional" e pautada

14. A distância temporal do Censo 2010, assim como as grandes transformações urbanas que provocaram o deslocamento compulsório de parcela significativa da população, impossibilita o cálculo das projeções para a população feminina por CISP, o que permitiria a realização da análise por taxa de 10 mil mulheres para outros anos.

15. O termo "ciclo da violência doméstica”, criado em 1979 pela psicóloga estadunidense Lenore Walker para identificar padrões abusivos em uma relação afetiva, continua sendo utilizado por psicólogos e defensores públicos especializados na defesa da mulher para identificar a violência doméstica. Para mais informações, ver: https://www.institutomariadapenha.org.br/violencia-domestica/ciclo-da-violencia.html. 
pela metáfora da guerra, não incorpora as mulheres como sujeitos de direito que devam ser consideradas na implementação de políticas públicas.

A Tabela 1 elenca as seis CISP e os respectivos bairros que apresentam as taxas mais altas de morte violenta de mulheres na cidade. Entre os bairros elencados, destacam-se os da Zona Oeste do Rio de Janeiro, especialmente aqueles localizados na Área de Planejamento 5 ( $\mathrm{AP}_{5}$ ), região cuja população é reconhecidamente mais negra e vulnerabilizada pela sistemática presença negligente do Estado. A região apresenta expansão urbana descontínua, com frequente ocupação de áreas irregulares e insuficiência de infraestrutura e serviços, além do baixo Índice de Desenvolvimento Social (IDS) ${ }^{16}$. Os dados sobre violência contra a mulher produzidos pelo ISP, por outro lado, evidenciam que violência, carência e vulnerabilidade caminham juntas.

A Tabela 2 apresenta o percentual de mulheres negras ou pardas vitimadas por esse tipo de crime o percentual de mulheres negras ou pardas vitimadas por esse tipo de crime. No ano de 2010, foram 128 casos de morte violenta de mulheres na cidade do Rio de Janeiro; em face do total de casos, o percentual de mulheres negras ou pardas vitimadas é de 55,4\%, o que já pode ser considerado grave, visto que a população autodeclarada negra ou parda na cidade, de acordo com o Censo de 2010, é de 47,9\%. Aqui, contudo, o recorte de raça das desigualdades territoriais se evidencia. Enquanto no centro da cidade apenas 33,3\% das mulheres vitimadas por homicídio doloso eram negras ou pardas, na $36^{\text {a }}$ CISP esse percentual chega a 68,76\%. Assim, o "racismo institucional", evidente na análise da cor das vítimas e que estrutura o planejamento urbano e a gestão territorial, vulnerabiliza ainda mais as mulheres negras.

\begin{tabular}{c|c|c}
\hline CISP & $\begin{array}{c}\text { Mulheres negras e pardas } \\
\text { vitimadas }\end{array}$ & $\begin{array}{c}\text { \% população negra e parda, } \\
\text { por CISP }\end{array}$ \\
\hline $1^{\mathrm{a}}, 4^{\mathrm{a}}, 5^{\mathrm{a}}$ & $33,3 \%$ & $46,4 \%$ \\
\hline $36^{\mathrm{a}}$ & $68,7 \%$ & $59,5 \%$ \\
\hline $39^{\mathrm{a}}$ & $50,0 \%$ & $63,2 \%$ \\
\hline $35^{\mathrm{a}}$ & $47,3 \%$ & $57,6 \%$ \\
\hline $43^{\mathrm{a}}$ & $66,6 \%$ & $65,6 \%$ \\
\hline $11^{\mathrm{a}}$ & $50,0 \%$ & $58,9 \%$ \\
\hline
\end{tabular}

Tabela 2. Percentual por CISP de mulheres negras ou pardas vitimadas em 2010

Fonte: Elaborada pela autora.

16. O IDS foi desenvolvido pelo Instituto Pereira Passos, autarquia da Prefeitura da Cidade do Rio de Janeiro, inspirado no Índice de Desenvolvimento Humano (IDH), incluindo outras dimensões que caracterizam o aspecto urbano. 
Por fim, na Tabela 3 estão elencados os bairros onde a taxa calculada para os casos de morte violenta de mulheres é mais significativa, assim como o percentual da população negra e parda por bairro. Esses dados demonstram a necessidade de aproximação territorial para possibilitar a compreensão do caráter estrutural do racismo em sua relação com as desigualdades territoriais e com a dinâmica do ciclo de violência que pode resultar em feminicídio. Assim, com exceção de bairros cuja taxa alta se relaciona diretamente com o baixo contingente populacional, os demais bairros apresentam o percentual de população negra e parda bastante superior diante da média da cidade.

\begin{tabular}{l|c|c|c} 
Bairro & CISP & Taxa & $\begin{array}{c}\text { \% população negra e parda } \\
\text { por bairro }\end{array}$ \\
\hline Saúde & $4^{\circ}$ & 0,73 & $50,3 \%$ \\
\hline Bonsucesso & $21^{\circ}$ & 0,30 & $39,4 \%$ \\
\hline Barros Filho & $39^{\circ}$ & 0,27 & $63,2 \%$ \\
\hline Urca & $10^{\circ}$ & 0,27 & $17,6 \%$ \\
\hline Cavalcanti & $29^{\circ}$ & 0,23 & $54,5 \%$ \\
\hline Estácio & $6^{\circ}$ & 0,22 & $51,3 \%$ \\
\hline Praça da Bandeira & $18^{\circ} / 19^{\circ}$ & 0,20 & $28,5 \%$ \\
\hline Costa Barros & $39^{\circ}$ & 0,20 & $69,5 \%$ \\
\hline Jacaré & $25^{\circ}$ & 0,20 & $65,8 \%$ \\
\hline Deodoro & $33^{\circ}$ & 0,17 & $63,2 \%$ \\
\hline São Conrado & $15^{\circ}$ & 0,17 & $16,7 \%$ \\
\hline Penha & $22^{\circ}$ & 0,15 & $54,5 \%$ \\
\hline Acari & $39^{\circ}$ & 0,14 & $65,2 \%$ \\
\hline Santíssimo & $35^{\circ}$ & 0,14 & $57,7 \%$ \\
\hline Del Castilho & $44^{\circ}$ & 0,12 & $40,6 \%$ \\
\hline Santa Cruz & $36^{\circ}$ & 0,12 & $65,6 \%$ \\
\hline
\end{tabular}

Tabela 3. Bairros com as maiores taxas de morte violenta de mulheres e percentual de população negra por CISP em 2010

Fonte: Elaborada pela autora.

O paradigma masculino e racista da segurança pública estruturante da "cidade patriarcal" e violenta se evidencia na observação da territorialização dos investimentos no tocante à segurança. O cartograma a seguir demonstra os locais onde a taxa de mortes violentas de mulheres no Rio de Janeiro é mais significativa ${ }^{17}$, bem como a localização dos locais de atendimento especializado à mulher,

17. Taxa para cada 10 mil mulheres segundo dados organizados com o cruzamento das informações do Censo 2010 (IBGE) e do ISP para o ano de 2010. 
em contraposição aos locais onde foram implantadas as UPPs ${ }^{18}$. Enquanto essas unidades de polícia, seguindo a agenda dos megaeventos esportivos, foram implantadas de forma consistente nas regiões turísticas da cidade e nos locais próximos às instalações esportivas, a insuficiência da rede de atendimento à mulher é óbvia.

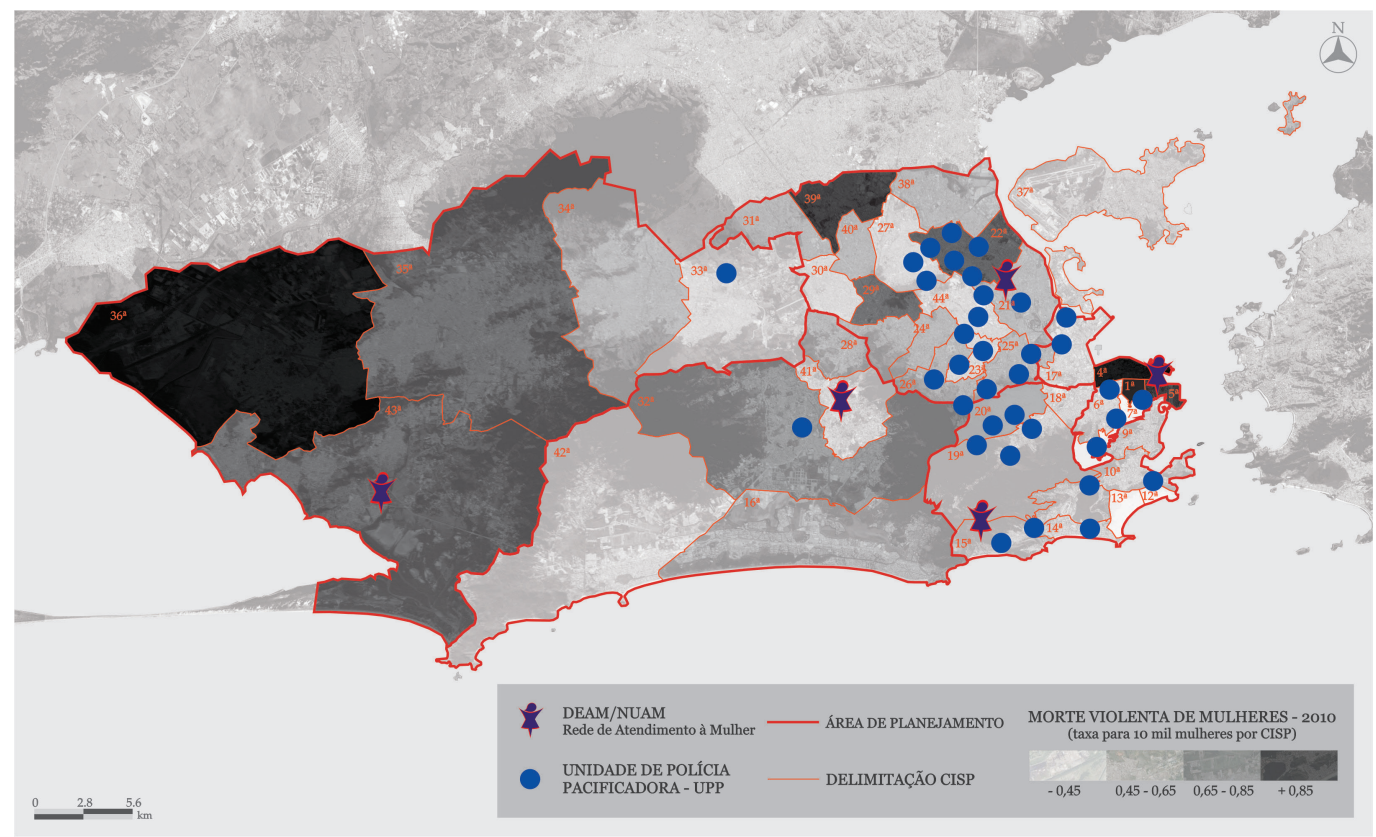

Figura 1. Morte violenta por taxa de 10 mil mulheres, por CISP, e localização das UPPs (2010) Fonte: Acervo do grupo de estudos Margear, 2020.

A rede especializada de atendimento à mulher foi ampliada no contexto do Programa Mulher: Viver sem Violência, implementado em 2013. Instituído pelo Decreto $\mathrm{n}^{\circ}$ 8.086/13 (BRASIL, 2013), tinha como objetivo integrar e ampliar os serviços públicos existentes voltados às mulheres em situação de violência. Nesse contexto, a cidade do Rio de Janeiro, que dispunha apenas de três Delegacias Especializadas de Atendimento à Mulher (DEAM) - situadas em Jacarepaguá, Campo Grande ${ }^{19} \mathrm{e}$

18. De acordo com dados da Prefeitura da Cidade do Rio de Janeiro, existem 37 UPPs instaladas nos seguintes territórios: Andaraí; Barreira do Vasco/Tuiuti; Batan; Borel; Cerró-Corá/Guararapes/Vila Cândido; Chapéu Mangueira/Babilônia; Cidade de Deus; Complexo da Penha; Complexo do Alemão; Complexo do Caju; Escondidinho/Prazeres; Fallet/Fogueteiro/Coroa; Formiga; Jacarezinho; Macacos; Mangueira; Manguinhos; Pavão-Pavãozinho/Cantagalo; Providência; Rocinha; Salgueiro; Santa Marta; São Carlos; São João; Tabajaras/Cabritos; Turano; Vidigal; Lins e Camarista Méier. Disponível em: http://www.rio.rj.gov.br/web/ipp/exibeconteudosocial?id=4677454. Acesso em: 27 maio 2021.

19. A DEAM de Campo Grande foi transferida provisoriamente para Pedra de Guaratiba em 2016, e, apesar dos protestos do movimento de mulheres e feminista da região, nunca retornou ao local de origem. Atualmente, a delegacia funciona na Estrada do Piaí, no bairro Pedra de Guaratiba, deixando desassistidas as mulheres de grande extensão territorial do município. 
no Centro -, implantou Núcleos de Atendimento à Mulher (NUAM) na Rocinha, no Alemão (no final de 2013) e no bairro Santa Cruz (em janeiro de 2014). O objetivo aqui não é discutir a eficácia ou não das UPPs, nem afirmar que mais polícia nos territórios necessariamente diminuiria a violência contra a mulher; o que se pretende é destacar onde e consequentemente a quem a agenda da segurança pública se dedica.

Além disso, de acordo com o relatório sobre a expansão das milícias no Rio de Janeiro, elaborado pelo Grupo de Estudos dos Novos Ilegalismos (Geni, ligado à Universidade Federal Fluminense) e pelo Observatório das Metrópoles (Instituto de Pesquisa e Planejamento Urbano e Regional da Universidade Federal do Rio de Janeiro), a implantação dos conjuntos do Programa Minha Casa, Minha Vida (PMCMV) se consolida como um novo vetor de expansão do poder das milícias no Rio de Janeiro, principalmente na Zona Oeste, onde o domínio dos milicianos se fortalece em decorrência de uma "gestão relacional, em que diferentes atores como síndicos, empresas de administração condominial e a própria prefeitura dividem responsabilidades e lucros" (HIRATA et al., 2021, p. 21).

O cartograma apresentado na Figura 2, produzido no âmbito da pesquisa supracitada, revela os pontos em que o conjunto de denúncias anônimas analisado comprova a atuação de grupos armados no território, além de demonstrar o número de operações policiais realizadas em 2007 e 2019, como forma de observar as vantagens políticas da milícia relacionadas à presença de agentes públicos em seus quadros, o que garante uma atuação praticamente irrestrita. Apesar de o recorte temporal ser mais amplo, a correlação entre as áreas de principal atuação de grupos armados na cidade e as áreas em que as taxas de violência contra a mulher são mais altas (Figura 1) pode ajudar a consolidar a hipótese de que, nos lugares em que o Estado democrático de direito não opera, o silenciamento, elemento estruturante do ciclo da violência, é dominante.

A Figura 3, por sua vez, demonstra o número de unidades licenciadas (20092020) por região administrativa, as unidades do PMCMV e a atuação das milícias na cidade do Rio de Janeiro. 


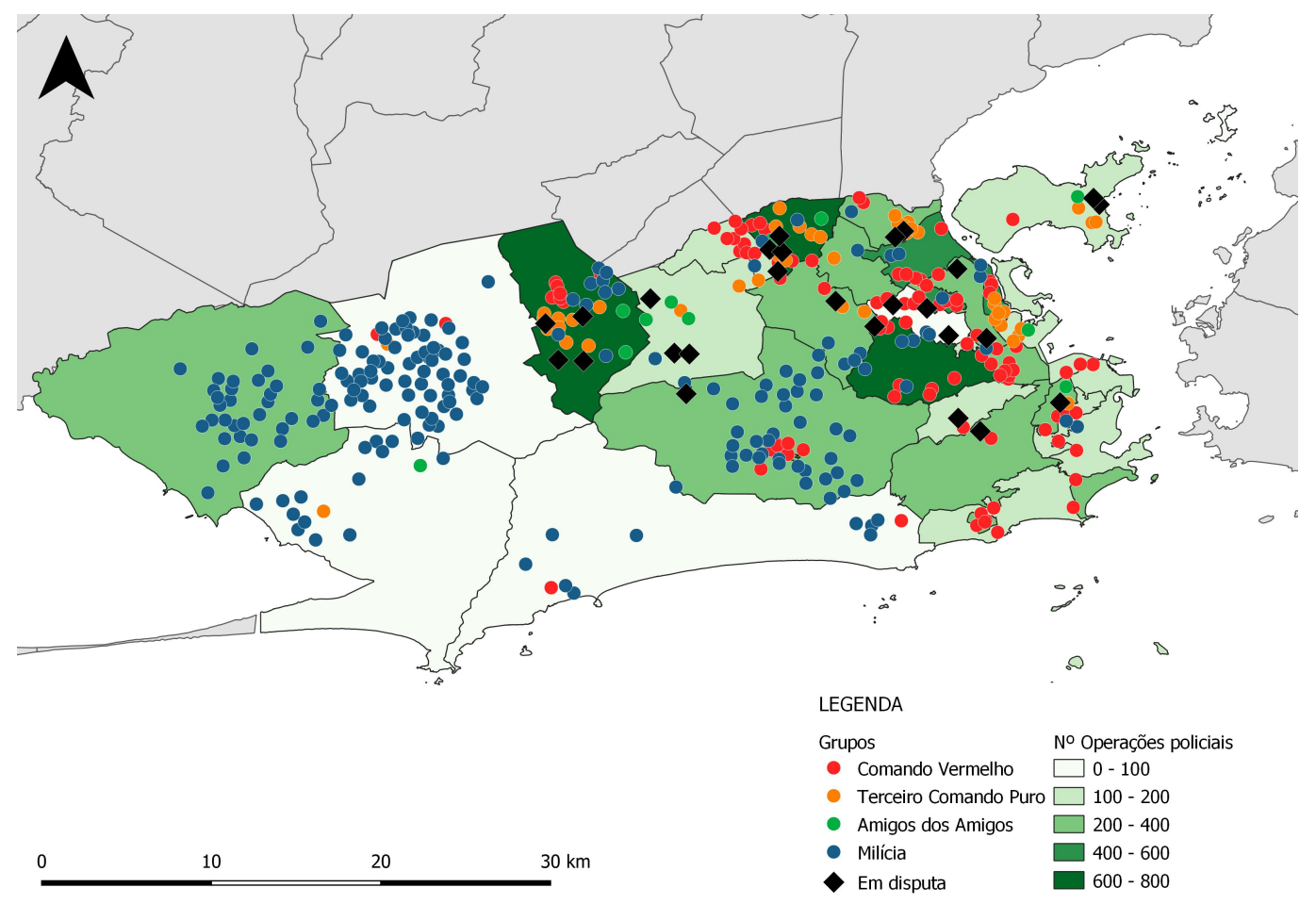

Figura 2. Número de operações policiais por região administrativas na cidade e grupos armados (2007-2019)

Fonte: Fonte: Geni/UFF e Disque-Denúncia.

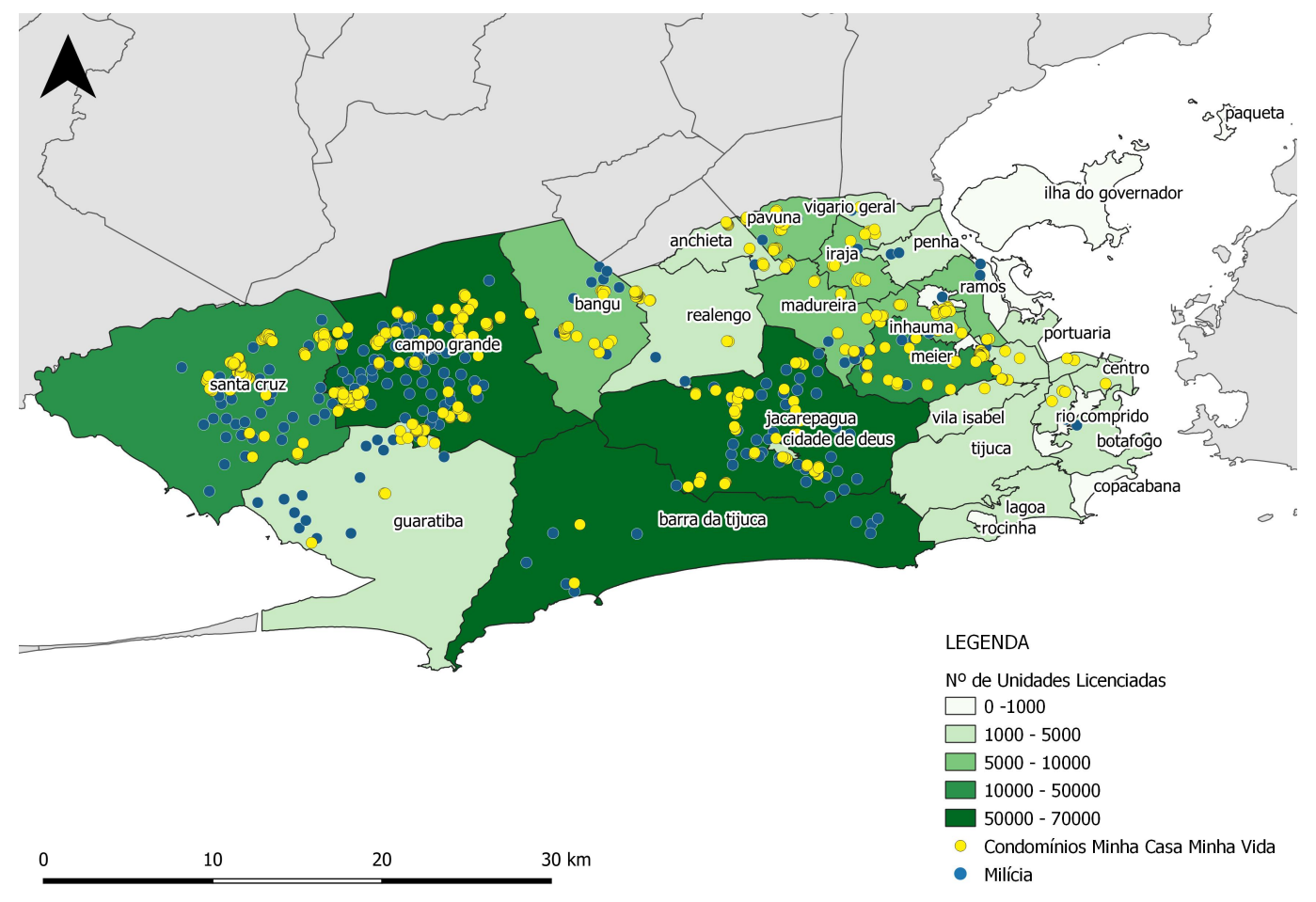

Figura 3. Número de unidades licenciadas por região administrativa, unidades do PMCMV e milícias na cidade do Rio de Janeiro (2009-2020)

Fonte: SMU e Mapa dos Grupos Armados do Rio de Janeiro. Elaborada pelo Observatório das Metrópoles e Geni/UFF. 
Nesse sentido, a hipótese aqui defendida é de que a conexão do Poder Público com a expansão do domínio das milícias determina a ausência do Estado democrático de direito como um fator agravante da violência contra a mulher e ainda permite a reflexão sobre a parcialidade da perspectiva que associa violência e pobreza. O cotidiano nesses locais opera com base na perspectiva de que "todo lugar tem um dono, cada um deve ficar no seu quadrado e andar na linha” (MONTEIRO, 2015, p. 129). Essa afirmação, mais do que uma percepção da realidade, se materializa profundamente como estratégia de sobrevivência. Nesses espaços, portanto, à revelia do que defende a crítica feminista, o pessoal não é político e, como em "briga de marido e mulher não se mete a colher", a violência contra a mulher encontra campo aberto para aprofundar o ciclo da violência vivenciado pelas mulheres periferizadas. Afinal, quem iria prestar socorro a uma mulher em situação de violência? A polícia? A milícia? Alguém?

Nesse sentido, o cartograma da Figura 4 demonstra, sob uma base na qual as taxas de morte violenta de mulheres por CISP estão representadas, os conjuntos do PMCMV implementados e os locais onde houve remoção no período de 2009 a 2014. Em síntese, foram removidas as famílias, boa parte delas chefiadas por mulheres, das regiões da cidade onde as taxas de violência contra a mulher são menores para as regiões onde as taxas são as mais altas da cidade.

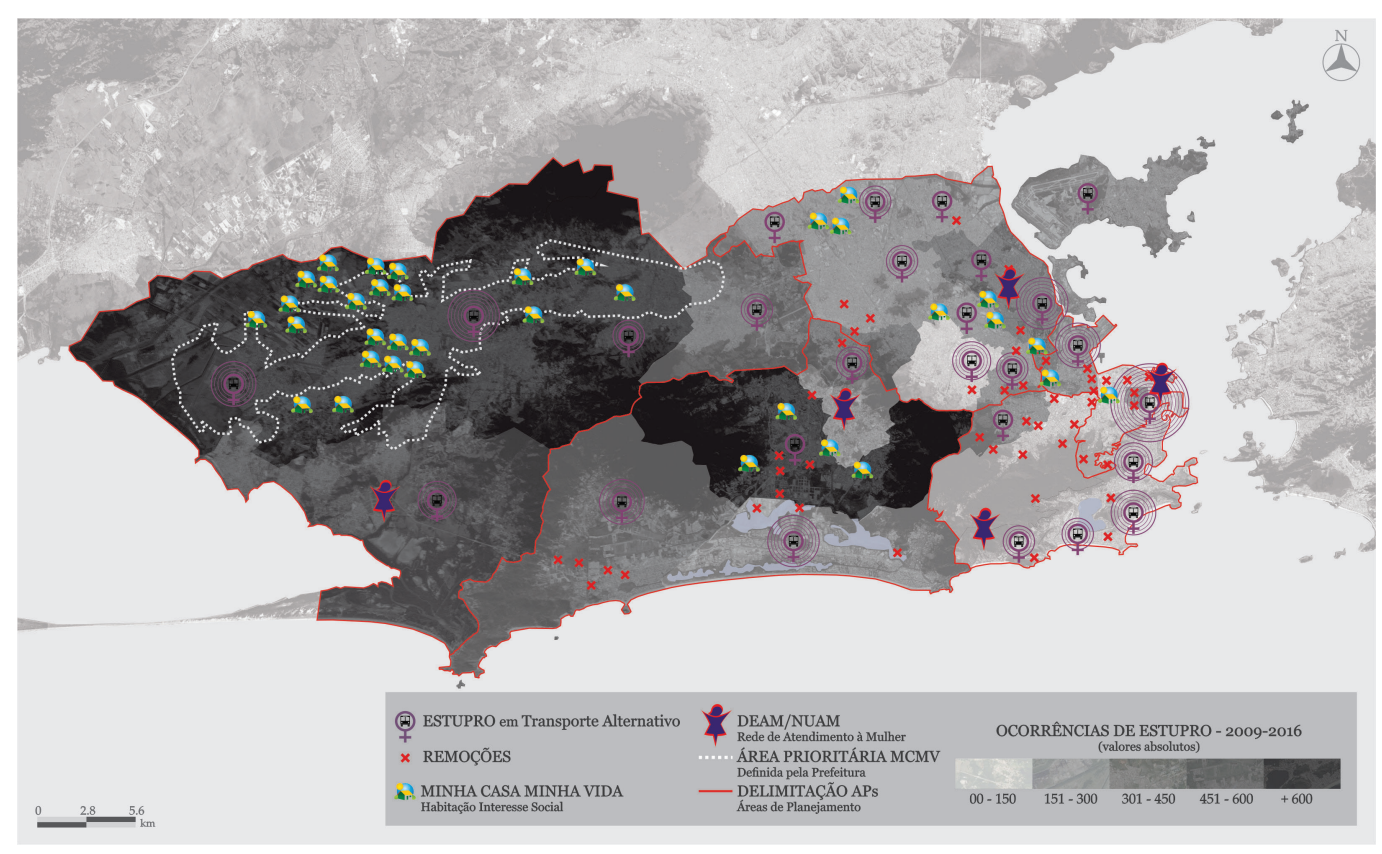

Figura 4. Localização dos empreendimentos do PMCMV para Habitação de Interesse Social e remoções efetivadas na cidade durante a gestão de Eduardo Paes (2009-2016)

Fonte: Elaborada pela autora, 2020. 
Além disso, a realidade cotidiana dos conjuntos habitacionais periféricos do PMCMV é ainda mais aguda para as mulheres. A remoção forçada implica a desconexão com a antiga localidade e a ruptura dos laços de solidariedade que possibilitavam, por exemplo, o trabalho feminino diante da ineficiência e da escassez de instituições públicas dedicadas ao cuidado e ao ensino infantil. A insuficiência dos serviços públicos dificulta o atendimento médico cotidiano e a manutenção das crianças na escola. A localização periférica posiciona as mulheres onde as oportunidades de trabalho são mais escassas e precarizadas, reforçando a posição da mulher como exército industrial de reserva responsabilizada pelas tarefas reprodutivas. A mobilidade focada exclusivamente no transporte pendular casa-trabalho dificulta o deslocamento no entorno da residência, o medo das ruas pode resultar na reclusão ao ambiente privado, e não na geração de renda autônoma. Todos esses fatores impactam a vida das mulheres e ampliam a vulnerabilidade que estrutura o ciclo da violência contra a mulher.

A impunidade penal considerada característica das mortes violentas de mulheres determina que o feminicídio é crime do Estado (LAGARDE, 2004), enquanto violação do Estado de direito, em virtude de as autoridades não cumprirem efetivamente suas funções. Essa perspectiva, associada à análise territorializada das políticas públicas com o aporte do recorte da interseccionalidade, permite inferir que o planejamento urbano, tal como é operado, está embebido do machismo institucional que segue vulnerabilizando as mulheres.

Nesse sentido, é relevante destacar que não se trata de ausência do Estado nesses territórios, e sim, como indica Leite (2012a, p. 377), de uma presença caracterizada pela prestação de serviços de baixa qualidade ou insuficientes, de clientelismo e ineficiência das instituições estatais, de brutalidade policial e desrespeito aos direitos civis. A análise territorializada dos dados sobre violência contra a mulher na cidade do Rio de Janeiro, portanto, evidencia a necessidade de ações integradas e inclusivas que não incorram de forma simplista e discriminatória na associação do fenômeno da violência com a pobreza ${ }^{20}$.

\footnotetext{
20. A associação entre pobreza e criminalidade é objeto de amplo debate. Ver: VALLADARES, L. Cem anos pensando a pobreza (urbana) no Brasil. In: BOSCHI, R. (org.). Corporativismo e desigualdade, a construção do espaço público no Brasil. Rio de Janeiro: Rio Fundo: Iuperj, 1991; VALLADARES, L. A invenção da favela: do mito de origem à favela. Rio de Janeiro: FGV, 2005; MACHADO DA SILVA, L. A. Violência urbana, segurança pública e favelas - o caso do Rio de Janeiro atual. Cadernos $C R H$, v. 23, n. 59, 2010; MACHADO DA SILVA, L. A. (org.) Vida sob cerco: violência e rotina nas favelas do Rio de Janeiro. Rio de Janeiro: Nova Fronteira, 2008; MACHADO DA SILVA, L. A.; LEITE, M. P.; FRIDMAN, L. C. Matar, morrer, civilizar: o problema da segurança pública. In: IBASE; ACTIONAID; FORD FOUNDATION (org.). Mapas: monitoramento ativo da participação da sociedade. Rio de Janeiro: Ibase, 2005. p. 1-35.
} 


\section{O paradigma masculino da segurança pública}

O debate dominante sobre a violência urbana no Rio de Janeiro, já há mais de dez anos, tem sido pautado pela ideia de "um novo modelo de segurança pública e de policiamento", que em teoria buscaria promover a interação entre população e polícia e o fortalecimento de políticas sociais nas favelas. A implantação das UPPs deveria responder ao sentimento de urgência relacionado aos crescentes índices de violência registrados na cidade ao longo das últimas décadas (CUNHA; MELLO, 2011). A ideia de levar paz aos territórios em guerra (CUNHA; MELLO, 2011) foi acionada constantemente, construindo a estratégia narrativa que legitimou a implantação das UPPs e mais tarde, já em um momento de forte crise financeira, política e social, a intervenção militar no Rio de Janeiro.

As favelas são percebidas pelo imaginário social dominante como territórios violentos, implicados por duas dimensões de ação. A primeira se associa ao crime organizado e à ideia de oposição entre crime e Estado, o que demandaria a ação violenta para o resgate da "paz" (por meio da implantação das UPPs, por exemplo). A segunda representa um juízo moral que define certos territórios como locais de sociabilidade incivilizada, o que demandaria a reintegração social para evitar a criminalidade (com a implantação da UPP social, por exemplo). As políticas de segurança pública destinadas a esses territórios, portanto, expressam essa percepção dominante. A narrativa sobre "uma cidade em guerra" foi construída na cidade do Rio de Janeiro em resposta a repetidos episódios violentos que produziram forte sentimento de insegurança em relação à integridade física e patrimonial. Nesse sentido, a "metáfora da guerra" se consolidou ao longo das décadas, impulsionada pela percepção do agravamento da situação de violência na cidade (LEITE, 2012a).

O padrão de atuação da polícia nos territórios empobrecidos e periféricos é reconhecidamente definido pelo abuso de autoridade e pelo uso da violência (CUNHA; MELLO, 2011). Nesse contexto, a presunção constitucional de inocência é negada às/aos moradoras/moradores de favelas, que passam a ser categorizadas/ os automaticamente como bandidas/os quando associadas/os ao seu local de moradia. A percepção da população favelada e periférica como criminosa não é exclusiva dos agentes de segurança pública - ela é hegemônica na sociedade. Nesse sentido, houve grande aceitação das UPPs por parte da opinião pública, que, convencida da necessidade de confronto com os "senhores da guerra" das favelas cariocas com vistas à contenção da violência urbana, saudou a implantação dessas unidades policiais. E, no contexto dos recorrentes atos de violência policial, como relata Perry (2017), são as mães e os membros das comunidades que realizam atos públicos pedindo justiça e o fim da violência estatal. As mulheres, portanto, estão 
cotidianamente na linha de frente na luta contra a guerra policial empreendida contra as comunidades pobres, e nesse contexto há um movimento consistente que denuncia o genocídio do povo negro no Brasil.

A narrativa a respeito da violência urbana, assentada sobre a ideia da "guerra", está profundamente relacionada à virilidade, a uma "corporalidade associada à masculinidade” (BIRMAN; CARLY, 2012, p. 61). A figura da “mãe”, nesse processo político de tensionamento entre visibilidade e ocultamento, expressa "uma insurgência política definida em estreitas conexões com as construções - sempre em processo - de gênero" (VIANNA; FARIAS apud FARIAS, 2015, p. 422), permitindo, assim, a "inscrição do feminino" no debate sobre violência urbana.

A construção social que anexa a inteligibilidade identitária da mulher à maternidade é estruturante do patriarcado. Ainda é dominante a ideia de que "é pela maternidade que a mulher realiza integralmente seu destino fisiológico" ou que "é a maternidade sua vocação 'natural', porquanto todo o seu organismo se acha voltado para a perpetuação da espécie” (BEAUVOIR, 1980, p. 248). Assim, como mães, as mulheres podem ascender à transcendência que é negada à sua imanente corporeidade objetificada. No entanto, mesmo a figura redentora da mãe, quando atravessada pelo recorte de classe, raça/etnia e território, não é capaz de passar ilesa diante do patriarcado. A declaração de Sérgio Cabral, ex-governador do Rio de Janeiro, de que as mulheres moradoras de favelas são "verdadeiras fábricas de marginais”21, expressa objetivamente a posição social destinada às mulheres que são mães, mas também negras e periféricas. É outro exemplo da estigmatização culpabilizadora do feminino e das mulheres em geral a perspectiva defendida publicamente pelo general Mourão $0^{22}$, quando ainda em campanha, de que famílias em que "não há pai e nem avô, é mãe e avó, torna[m]-se uma fábrica de elementos desajustados, e que tendem a ingressar nessas narcoquadrilhas”.

É importante perceber que não se trata de opiniões pessoais: é uma perspectiva hegemônica de uma sociedade construída sobre bases patriarcais, coloniais e racistas, que faz das mulheres uma "população problema" sobre a qual devem incidir as "técnicas de governo" que se configuram como propostas de "tratamento epidemiológico da população favelada” (BIRMAN apud FARIAS, 2015, p. 424).

\section{A sociabilidade violenta e a rotina das mulheres}

A violência sexista, de acordo com Davis (2017), não é imanente dos homens e não se perpetua por conta de um impulso incontrolável; sendo estrutural, ela é

21. Disponível em: https://www1.folha.uol.com.br/fsp/cotidian/ff2510200701.htm. Acesso em: 13 ago. 2009. 22. Disponível em: https://www.youtube.com/watch?v=AMc1Lx84mak. Acesso em: 20 set. 2018. 
reproduzida pelo conjunto da sociedade, e sua prática extrapola simples vontades individuais. A masculinidade violenta, socialmente construída, externaliza a materialidade da violência cotidiana que permite e legitima o exercício de poder sobre as mulheres. A pressão econômica, social e política, que determina a "sociabilidade violenta”, pode ser um fator de perpetuação da violência contra a mulher, considerando que, de acordo com Machado da Silva (2010), o funcionamento dos sistemas político-institucionais, por mais contraditórios que sejam em sua atuação, que combina controle e proteção sociais, são ainda mais frágeis nos "territórios da pobreza”. Além disso, a deficiência dos serviços públicos, a subalternidade política relacionada ao clientelismo, o padrão de trabalho informal e precarizado e o isolamento territorial podem intensificar os padrões patriarcais que facilitam a perpetuação do ciclo de violência que vulnerabiliza as mulheres periféricas. Assim, a certeza da impunidade relativa à ausência do Estado democrático de direito nos territórios periferizados e empobrecidos, em adição à mistificação machista, que segue atribuindo a culpa às vítimas (DAVIS, 2017), resulta na invisibilização das mulheres que continuam "tombando" na "guerra” dos homens. Portanto, é importante pensar a inclusão do debate sobre violência contra a mulher na reflexão geral sobre segurança pública.

A morte violenta de mulheres, até bem pouco tempo, não era tratada como um homicídio cujo responsável deveria ser punido. A ideia de "crime passional" ainda hoje permeia o imaginário popular sobre mulheres vítimas de assassinato. $\mathrm{E}$ a forma como a mídia dominante trata o tema evidencia o tensionamento entre visibilidade e ocultamento. A Figura 5 diz respeito à ocorrência dos termos "crime passional” e "feminicídio" no jornal $O$ Globo ${ }^{23}$ nos últimos dez anos, considerando a publicação em âmbito nacional. As informações no eixo vertical demonstram, em valores absolutos, o número de ocorrências dos dois termos e sugerem que a inflexão da ocorrência da expressão "crime passional” a partir de 2015 é reflexo da luta das mulheres pela tipificação penal do feminicídio, o que certamente contribuiu para visibilizar a violência contra a mulher. Esse processo manifesta a importância dos tensionamentos epistêmicos na luta pelo posicionamento das mulheres como sujeitas de direito.

23. De acordo com o ranking da Agência Zenithoptimedia, o Grupo Globo, do qual o citado jornal é integrante, é o maior conglomerado de mídia e comunicação do Brasil e da América Latina. Na cidade do Rio de Janeiro, é um grande formador da opinião pública. 


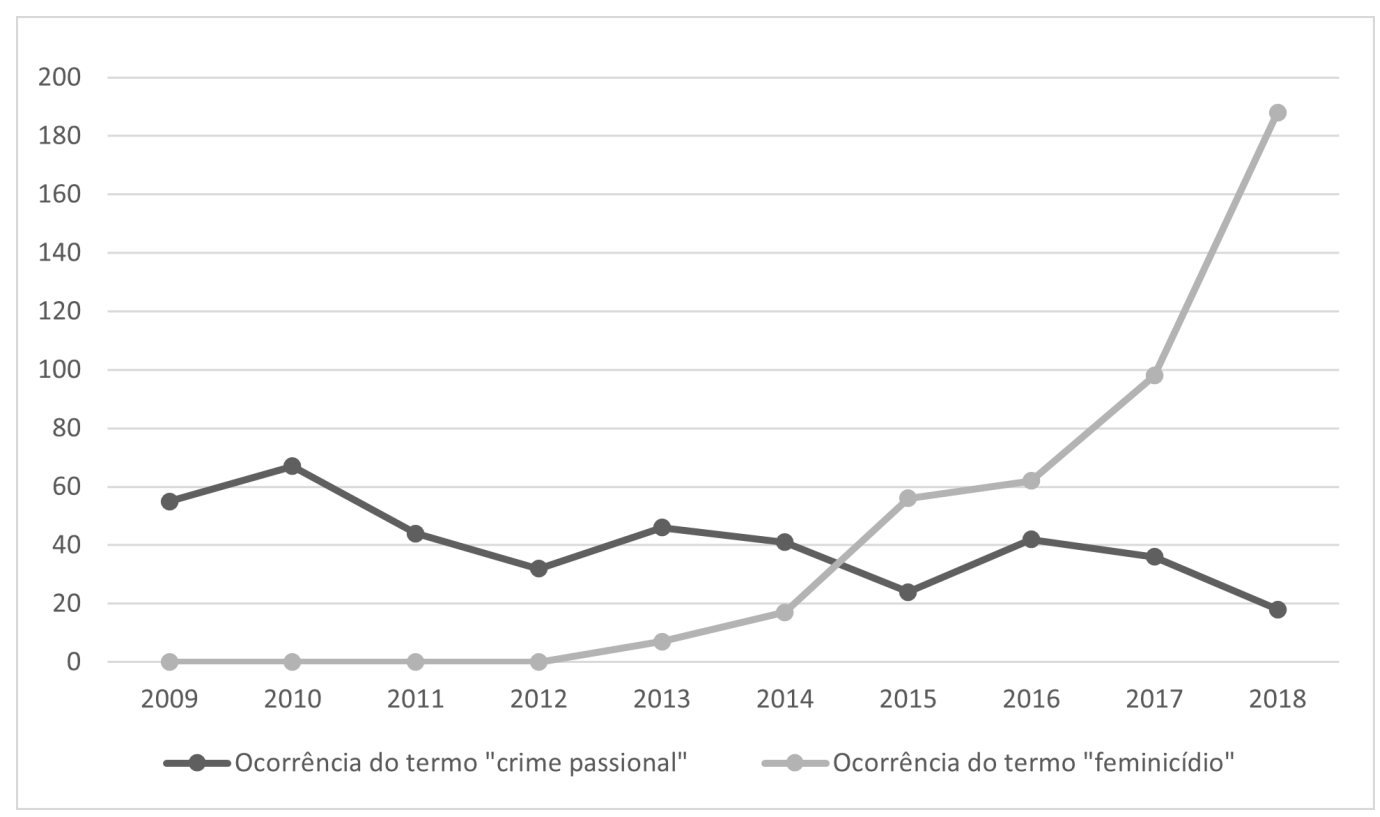

Figura 5. A morte violenta de mulheres na perspectiva da mídia dominante Fonte: Elaborada pela autora, 2020.

A narrativa da violência como problema urbano foi formulada há pouco mais de duas décadas (BIRMAN; CARLY, 2012). A violência contra a mulher, entretanto, não figura efetivamente no debate sobre planejamento urbano, e tampouco na concepção do que é segurança pública. A Câmara dos Deputados reconhece no documento Agenda de segurança cidadã: por um novo paradigma que "o direito à vida segura ainda não é realidade para amplas parcelas da população brasileira. Os feminicídios e estupros acontecem todos os dias” (BRASIL, 2018, p. 16). Está explícita no documento a necessidade de conceber uma "política de redução de homicídios, focalizando os territórios e públicos em que se concentram as mortes violentas, [...], estabelecendo metas para redução por faixas etárias, territórios, grupos raciais e gênero" (BRASIL, 2018, p. 18). Esse reconhecimento desejável, porém, tardio, da questão possivelmente está relacionado com a tipificação do crime de feminicídio.

As rotinas das quais a agenda da segurança pública atualmente se ocupa, entretanto, são aquelas vinculadas à reprodução do capital. A simplificação e o reducionismo da questão da violência urbana determinam que a manutenção da ordem pública se paute na "guerra" contra as "atividades que perturbam o prosseguimento rotineiro da vida social" e implique a culpabilização da população moradora de favelas (MACHADO DA SILVA, 2010, p. 293). O que acontece é que a "guerra" se direciona contra a população (LEITE, 2012a).

Mas, para além dessa questão, as rotinas das mulheres em situação de violência não estão efetivamente no escopo. Considerando que as mulheres "constituem o 
exército de reserva das economias capitalistas modernas” (SAFFIOTI, 2014, p. 489), tais rotinas não interessam diretamente ao capital ${ }^{24}$. Assim, o violento cotidiano delas não integra a agenda pública, uma vez que está posicionado segundo a perspectiva dominante da sociedade como questão privada. O processo de segregação urbana e periferização da moradia confronta as mulheres de maneira mais aguda, não somente pela ausência de infraestrutura urbana básica e serviços essenciais, como também pela violência urbana. $\mathrm{O}$ feminicídio é um fenômeno predominantemente domiciliar, contudo $31,2 \%$ dos casos acontecem nas ruas, sobretudo nas ruas das periferias, atingindo em particular mulheres negras e pobres.

\section{Considerações finais}

Na reflexão desenvolvida ao longo deste texto, é fundamental compreender que a esfera pública, na qual são geradas e geridas as políticas públicas, é determinante para a segurança e a autonomia das mulheres. Por outro lado, é necessário enfatizar que a atuação do Estado não vai mover as estruturas do patriarcado e do racismo; adicionalmente, as lutas feministas não podem estar submetidas à ampliação de instituições burguesas. O tensionamento dessas estruturas permanece uma pauta necessária para as lutas cotidianas e a sobrevivência das mulheres, visto que o enfrentamento desse tipo de violência parece estar vinculado à atuação do Estado nos territórios, mas não é central na luta para modificar tais estruturas.

$\mathrm{O}$ isolamento territorial e, consequentemente, a dificuldade de acesso às leis e aos serviços ampliam a vulnerabilidade de mulheres que vivenciam o cotidiano violento em áreas dominadas pelo crime organizado. O sistema de justiça e as políticas de segurança pública precisam ser expandidos, e mecanismos eficazes e adaptados às diferentes necessidades devem apoiar o combate à violência contra $\mathrm{a}$ mulher em âmbito nacional. A prevenção à violência, contudo, é um aspecto fundamental de uma ação contínua. Por isso é tão importante que as políticas públicas sejam elaboradas de forma integrada e multidisciplinar, incorporando a segurança pública na formulação de políticas de habitação de interesse social, mobilidade, educação e saúde, para com isso romper o suposto universalismo das políticas públicas concebidas por homens sob a premissa do patriarcado.

Diante dos dados analisados, acreditamos que o planejamento urbano implementado no Rio de Janeiro nos últimos anos se conforma como um elemento

24. Uma pesquisa realizada recentemente pelo Serviço de Proteção ao Crédito (SPC) e pela Confederação Nacional de Dirigentes Lojistas (CNDL) mostra que uma mulher com filhos, com ensino médio completo e 34 anos, em média, correspondia ao perfil da pessoa desempregada no Brasil em 2018. Disponível em: https://exame.abril.com.br/economia/quem-sao-os-desempregados-brasileiros-em-2018/. Acesso em: 16 fev. 2019. 
de ampliação do número de mulheres vulneráveis à violência, de diversas formas: promovendo remoções massivas, as quais fragilizam as redes de apoio da vivência cotidiana e deslocam milhares de famílias para regiões periferizadas na cidade, carentes de investimento público em infraestrutura e atingidas por altos índices de violência, amplificados pelo processo de militarização da vida. A negação da mulher como sujeito de direitos é demonstrada na observação das prioridades da agenda de segurança pública materializada no espaço urbano. A contraposição entre as UPPs e as DEAM, tanto em termos de localização como de investimento, evidencia como o caráter estrutural do patriarcado invisibiliza as mulheres na definição de prioridades públicas e como o planejamento urbano pode ser uma ferramenta patriarcal e racista.

Acreditamos ainda, baseados na reflexão apresentada por Perry (2017), que o caso do Rio de Janeiro é exemplar para compreender a interface do planejamento urbano com a violência contra as mulheres, especialmente as periferizadas, pauperizadas e negras, de grandes cidades dos países periféricos. Por essa razão, posicionamos a interseccionalidade como uma chave de compreensão fundamental para a compreensão territorializada da imbricação entre políticas públicas, violência e planejamento urbano no Rio de Janeiro, para finalmente buscar formas de enfraquecer a dinâmica de demarcação de territórios como "zonas de não-ser". Mas, na luta pelo existir, o sujeito coletivo mulheres, com suas estratégias que estabelecem uma nova ética política baseada no cuidado e nas relações cotidianas, consolida uma estratégia não somente de resistência, mas também de combate aos avanços nas constantes tentativas de retirada de direitos (MONTEIRO; MEDEIROS; NASCIUTTI, 2017).

\section{Referências}

AKOTIRENE, C. Interseccionalidade. São Paulo: Polén, 2019.

BEAUVOIR, S. de. O segundo sexo: a experiência vivida. Tradução: Sérgio Milliet. Rio de Janeiro: Nova Fronteira, 1980. [1949]

BIRMAN, P.; MACHADO, C. A violência dos justos: evangélicos, mídia e periferias da metrópole. Revista Brasileira de Ciências Sociais, São Paulo, Anpocs, v. 17, n. 80, 2012.

BRASIL. Decreto $\mathrm{n}^{\circ}$ 8.086, de 30 de agosto de 2013. Institui o Programa Mulher: viver sem violência e dá outras providências. Diário Oficial da União, Brasília, DF, 30 ago. 2013.

Câmara dos Deputados. Agenda de segurança cidadã: por um novo paradigma. Relator: Paulo Teixeira. Brasília, DF: Câmara dos Deputados: Edições Câmara, 2018. Disponível em: http://bd.camara.gov.br/bd/handle/bdcamara/35519. Acesso em: 13 fev. 2019. 
COLLINS, P. H. Se perdeu na tradução: feminismo negro, interseccionalidade e política emancipatória. Revista Parágrafo, v. 5, n. 1, p. 6-17, jan.-jun. 2017.

CUNHA, N. V.; MELLO, M. A. da S. Novos conflitos na cidade: o processo de urbanização na favela. Dilemas - Revista de Estudos de Conflito e Controle Social, v. 4, n. 3, 2011.

DAVIS, A. Mulheres, raça e classe. Tradução: Heci Regina Candiani. São Paulo: Boitempo, 2016.

FARIAS, J. Da capa de revista ao laudo cadavérico: pesquisando casos de violência institucional em favelas cariocas. In: BIRMAN, P.; LEITE, M.; MACHADO, C.; CARNEIRO, S. de S. Dispositivos urbanos e trama dos viventes. Ordens e resistências. Rio de Janeiro: FGV; Faperj, 2015.

FAULHABER, L.; AZEVEDO, L. SMH 2016: remoções no Rio de Janeiro Olímpico. Rio de Janeiro: Mórula, 2015.

HIRATA, D. et al. A expansão das milícias no Rio de Janeiro: uso da força estatal, mercado imobiliário e grupos armados. Rio de Janeiro: Fundação Heinrich Böll, 2021.

IBGE. Instituto Brasileiro de Geografia E Estatística. Censo Brasileiro de 2010. Rio de Janeiro: IBGE, 2012.

LAGARDE, M. Por la vida y la libertad de las mujeres: Fin al feminicidio. Juárez, México: Comisión Especial Del Feminicidio (LIX Legislatura), 2004. Disponível em: http://www. cimacnoticias.com.mx/especiales/comision/diavlagarde.htm. Acesso em: 30 maio 2018.

LEITE, M. P. Da "metáfora da guerra” ao “projeto de pacificação”: favelas e segurança pública no Rio de Janeiro. Revista Brasileira de Segurança Pública, v. 6, n. 12, 2012a.

. A faxina étnica: preconceito racial e racismo institucional no Brasil. Le Monde Diplomatique, Rio de Janeiro, n. 6o, .jul, 2012b. Disponível em: https://diplomatique.org. br/preconceito-racial-e-racismo-institucional-no-brasil/. Acesso em: 18 out. 2018.

MACHADO DA SILVA, L. A. Violência urbana, segurança pública e favelas - o caso do Rio de Janeiro atual. Cadernos CRH, v. 23, n. 9, 2010.

MAROULI, C. Women resisting (in) the city: struggles, gender, class and space in Athens. International Journal of Urban and Regional Research, 19(4), p. 534-548, 1995.

MONTEIRO, P. O gênero da habitação: a diretriz de titulação feminina no marco do Programa Minha Casa Minha Vida. 2015. Dissertação (Mestrado em Planejamento Urbano e Regional) - Universidade Federal do Rio de Janeiro, Rio de Janeiro, 2015.

MONTEIRO, P.; MEDEIROS, M.; NASCIUTTI, L. Insurgência feminina: a ética do cuidado e a luta contra a remoção. ENCONTRO NACIONAL DA ASSOCIAÇÃO NACIONAL DE PÓS-GRADUAÇÃO E PESQUISA EM PLANEJAMENTO URBANO E REGIONAL, 17., 2017, São Paulo. Anais [...]. São Paulo: Anpur, 2017. Tema: Desenvolvimento, crise e resistência: Quais os caminhos do Planejamento Urbano e Regional? Disponível em: http:// anpur.org.br/xviienanpur/principal/publicacoes/XVII.ENANPUR_Anais/ST_Sessoes_ Tematicas/ST\%209/ST\%209.3/ST\%209.3-03.pdf. Acesso em: 25 mar. 2018. 
PATEMAN, C. Críticas feministas à dicotomia público/privado. In: MIGUEL, L. F.; BIROLI, F. (org.). Teoria política feminista: textos centrais. Vinhedo: Horizonte, 2013. p. 55-80.

PERRY, K.-K. Black women and state-sanctioned violence in the Brazilian city. Spotlight on race, justice, and the city. International Journal of Urban and Regional Research, 2017. Disponível em: https://www.ijurr.org/spotlight-on/race-justice-and-the-city/black-women-and-state-sanctioned-violence-in-the-brazilian-city/. Acesso em: 25 set. 2020.

SAFFIOTI, H. I. B. Quem tem medo dos esquemas patriarcais de pensamento? Dossiê Crítica Marxista, n. 11, Campinas: Unicamp, p. 71-75, 2000. Disponível em: https://edisciplinas. usp.br/pluginfile.php/4300345/mod_resource/content/1/SAFFIOTI\%2C\%20Heleieth.\%20 Quem\%2otem\%2omedo\%2odos\%2osistemas\%2opatriarcais\%2ode\%2opensamento. pdf. Acesso em: 19 jan. 2015.

. Gênero, patriarcado, violência. 2. reimp. São Paulo: Fundação Perseu Abramo, 2011. (Coleção Brasil Urgente).

. A mulher na sociedade de classes: mito e realidade. 3. ed. 1. reimp. São Paulo: Expressão Popular, 2014.

SILVA, J. M. Gênero e sexualidade na análise do espaço urbano. Revista Geosul, Florianópolis, UFSC, v. 22, p. 117-134, 2007. 


\section{Poliana Gonçalves Monteiro}

Arquiteta popular e urbanista pela Universidade Federal de Juiz de Fora (UFJF) e mestra em Planejamento Urbano e Regional pela Universidade Federal do Rio de Janeiro (IPPUR/ UFRJ). Doutoranda em Arquitetura e Urbanismo pela Universidade Federal Fluminense (PPGAU/UFF). Pesquisadora no Laboratório Estado, Trabalho, Território e Natureza (ETTERN/IPPUR/UFRJ) e participante do grupo Grandes Projetos de Desenvolvimento Urbano (GPDU/UFF). Atua como assessora técnica de favelas ameaçadas por processo de remoção e em movimentos sociais de luta pela moradia. É colaboradora do curso Promotoras Legais Populares da Faculdade Nacional de Direito da UFRJ. Atualmente é professora no Programa de Pós-graduação Lato Sensu em Desenvolvimento Regional e Sustentabilidade do Instituto Federal de Educação, Ciência e Tecnologia do Rio de Janeiro (IFRJ-Pinheiral), além de assessora parlamentar no mandato da vereadora Monica Benicio.

Email: poli.dmambembe@gmail.com

ORCID: 0000-0002-0823-7630

Submissão: 17 de dezembro de 2020.

Aprovação: 26 de julho de 2021.

Como citar: MONTEIRO, P. A guerra dos homens e a vida das mulheres. As interfaces entre planejamento urbano, violência contra a mulher e segurança pública no Rio de Janeiro, Brasil. Revista brasileira de estudos urbanos e regionais. Dossiê Território, Gênero e Interseccionalidades. v. 23, E202131, 2021. DOI 10.22296/2317-1529.rbeur.202131

Artigo licenciado sob Licença Creative Commons CC BY 4.0.

https://creativecommons.org/licenses/by/4.o/deed.pt_BR 